In contrast to shifts in other European countries in the late 1990s, the Austrian position on agricultural biotechnology has remained constant over the past decade. Although Austria's position was initially considered restrictive in comparison, developments elsewhere narrowed the gap, and the European Commission adopted measures that Austria had endorsed for a long time. Taking Austria as an example, this article considers some frequent explanations for the transatlantic divide in agricultural biotechnology that emphasize the link between public opinion and policy. Such explanations stress nongovernmental organizations and media campaigns triggering technophobia among an uninformed public, governments giving in to public pressure and abandoning sound science, and protectionism in agricultural policy that prevents free trade. While not entirely to be dismissed, there also are arguments against a cause-effect relationship between public pressure and policy. Differences in the perceived roles of agriculture seem more important, however.

\title{
Austria and the Transatlantic Agricultural Biotechnology Divide
}

HELGE TORGERSEN

Austrian Academy of Sciences

The transatlantic divide in biotechnology has many sources, such as profound differences in research infrastructure, patenting laws, financial markets, and industry structure, among others. Public attitudes have additionally contributed especially to the reluctant adoption of agricultural biotechnology in Europe. In this article, I address some frequently met arguments about public perceptions and their influence on policy that could have led to Europe increasingly lagging behind North America in recent years. I use the example of Austria, which is a tiny country compared to the entire European Union (EU) or the United States but is interesting because it had already adopted a restrictive policy at a point in time when there was more supportive policy in

Author's Note: Address correspondence to Helge Torgersen, Institute of Technology Assessment, Austrian Academy of Sciences, Strohgasse 45, A-1030 Vienna, Austria; telephone: 43-151581-6588; fax: 43-1-7109883; e-mail: torg@ oeaw.ac.at.

Science Communication, Vol. 24 No. 2, December 2002 173-183

DOI: $10.1177 / 107554702237843$

(C) 2002 Sage Publications 
other countries. Austria thus can be taken as an early case for developments around agricultural biotechnology that have been observed within the EU over the past couple of years.

\section{Austria as a Forerunner}

From an outside perspective, the European position on genetically modified organisms (GMOs) appears fairly homogenous. During the late 1990s, the EU as a whole seemed to have shifted to a more restrictive policy. A closer look, however, reveals profound differences from country to country. What appears to be "the" European stance is the result of a complicated balancing of different countries' changing views and interests through the European institutions, which themselves add another political layer. In particular, the European Commission-in its attempt to harmonize diverging positionshas a double role, being both an integrator and an important player. Within attempts to harmonize, member countries have always differed in their impact on the overall "European" position. Among those that for a long time have exercised prominent influence on biotechnology policy are France, the United Kingdom, and (partly) Germany, but also smaller countries such as Denmark and the Netherlands.

Austria, in contrast, was hardly visible in terms of political influence, although in retrospect, the Austrian policy seemed to anticipate early elements of what was to come later in other European countries. Already during the early 1990s, the Austrian position on agricultural biotechnology was restrictive compared to the positions of other member countries (Grabner and Torgersen 1998). Until the mid-1990s, and even later, many policymakers and experts considered the Austrian stance to be so awkward that they literally did not take it seriously. In late 1995, however, after the pending import of genetically modified (GM) maize and soy from the United States, public controversies arose over almost all of Europe.

Suddenly, it had become clear that plant biotechnology and food issues were closely linked. In Austria, this link had already been established, and the Austrian position remained more or less unchanged after 1996 and 1997, while other countries revised their policies and adopted more restrictive measures. While dissenting countries such as Austria sooner or later would have been brought back to the mainstream within the EU, the very mainstream began to change. The combined shifts in several countries' positions prompted the European Commission to redefine its policy concerning the pending revision of the release directive $90 / 220$ and to issue a temporary halt to new marketing applications (the so-called de facto moratorium). It 
ultimately resulted in the official adoption of the precautionary principle ${ }^{1}$ and other elements that the United States and Canada consider prone to nontariff trade barriers.

Many have speculated why the European position has turned so negative toward agricultural biotechnology. Different explanations have been offered, but the evidence is inconclusive (Gaskell et al. 2001b). In this article, I investigate some frequent and partially overlapping explanations for this shift. Because Austria had early taken a stance that became more common during the late 1990s, I use Austria as an example to briefly explore four questions. Did nongovernmental organizations (NGOs) impose their extremist views on an uneducated public? Did mass media campaigns support a widespread and general technophobia among laypeople? Did governments give in to public pressure and abandon sound science in regulatory decisions? And finally, with respect to agricultural policy, in which way, if at all, are European countries protectionist?

\section{The Role of NGOs}

A frequently heard explanation for why Europe shifted to such a negative position toward agricultural biotechnology is that environmentalist NGOs imposed aversion to biotechnology on a scientifically illiterate public. This explanation suggests that environmental and consumer NGOs exaggerated fears and invented "facts" to support mistaken arguments and that a lack of factual knowledge prompted the public to believe the arguments and to resist the proper implementation of biotechnology as a safe and efficient way to enhance productivity.

Several Eurobarometer surveys on the public perception of biotechnology carried out during the 1990s in all EU member countries showed that the general public indeed knows little about the relevant science. However, parallel surveys have shown that both in Austria (as in the whole of Europe) and in the United States, the relationship between education or biological knowledge and a positive evaluation of biotechnology is rather weak (Priest 2000). Additionally, the finding that those with higher textbook knowledge are more in favor of biotechnology can also be interpreted as a result of the "white male protestant" phenomenon: those who are better educated are usually more privileged, more likely to be in control, and hence have a better chance to gain from new developments.

The NGO-lay public explanation also suggests that NGO activity preceded the rejection of agricultural biotechnology. At least in the case of Austria, this explanation cannot be sustained. In comparison to other European 


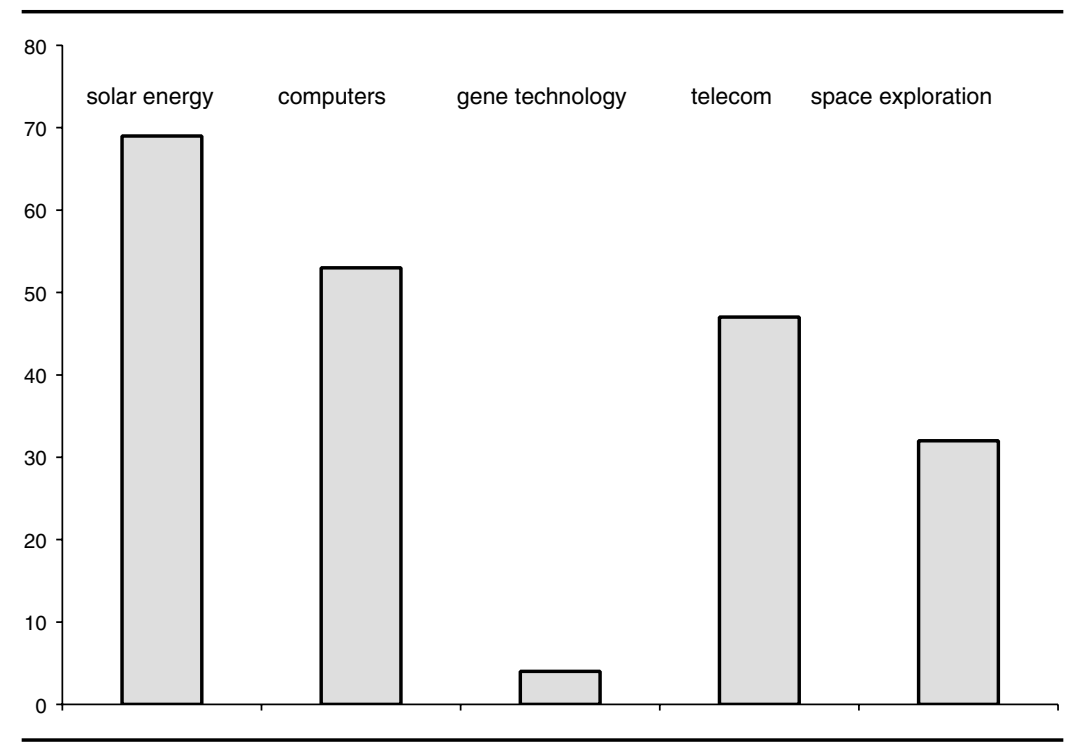

Figure 1: Technological Optimism in Austria, 1993

SOURCE: Adapted from Torgersen and Seifert (1997).

countries such as Denmark and Germany, Austria saw a very delayed public debate, and up to 1996, Austrian NGOs showed virtually no interest in biotechnology at all. This is not to say that agricultural biotechnology ever met acceptance in Austria: surveys performed in the early 1990s indicated that public attitudes were quite negative (Torgersen and Seifert 1997), and they have remained so ever since. This attitude, however, was latent, while open political protest was noticeable only after NGOs had framed the debate. Hence, NGOs did not seem to invent or impose such attitudes on the public; rather, they brought them to light (Figure 1).

\section{The Technology-Averse Public}

Another explanation is that the general public has an antitechnology attitude. However, although Austrians tend to express less enthusiasm for new technologies as compared to most Europeans, one cannot call them technology averse in a general sense. For example, the swift diffusion of cellular phones, pushing Austria to a top place within only a few years, shows that new technology as such is not the problem.

Rather, Austrians (as well as others) abhor certain large-scale, expertsteered technological systems, such as nuclear power, that carry menacing 


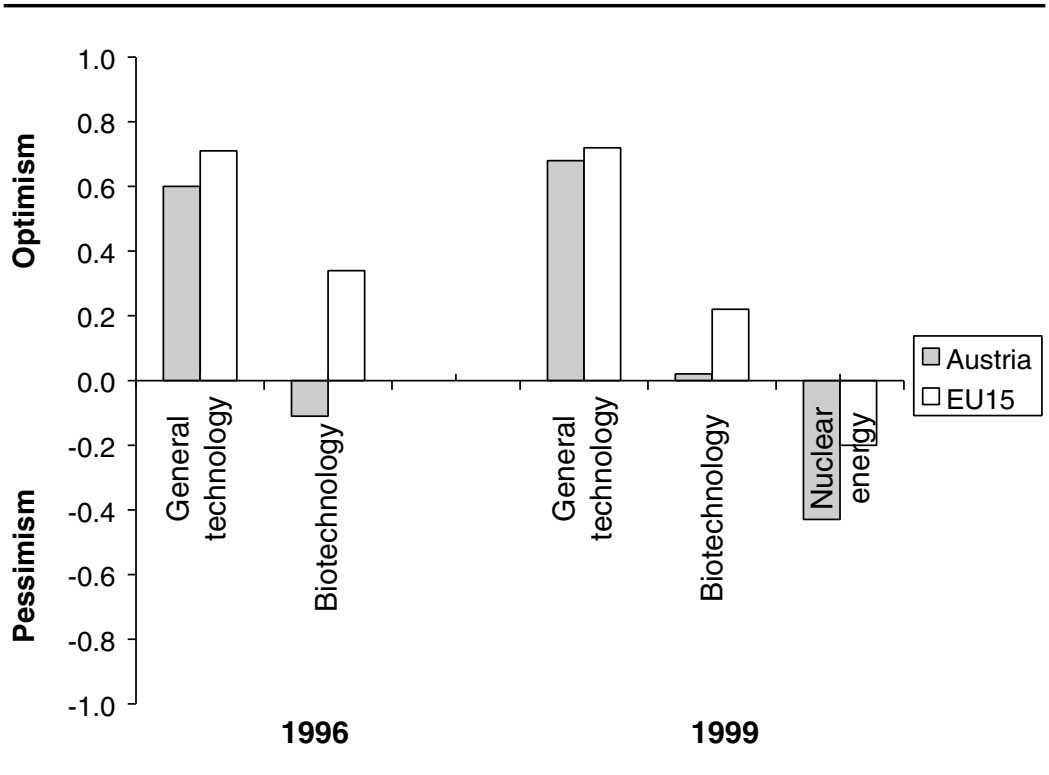

Figure 2: Technological Optimism in Austria versus the European Union (EU), 1996 versus 1999

SOURCE: Torgersen et al. (2001), reprinted with permission from the Science Museum,

London.

images. Biotechnology, for some reason, rhetorically falls into the same category. Risk with respect to food was another type of hazard that in Austria always was considered especially threatening. For example, although there was no bovine spongiform encephalopathy (BSE) case in Austria up to late 2001, during the BSE crisis of the mid-1990s, beef sales went down considerably, exceeding the effects in other countries that were heavily stricken by the disease (Figure 2).

The negative image of agricultural biotechnology has not the least to do with its perceived lack of benefit for individuals. In Austria, as elsewhere in Europe, GM crops were considered to benefit only industry, not consumers (Wagner et al. 2001). While across the Atlantic, even those who do not directly profit perceive economic competitiveness to be an asset (Priest 2000), this may be different in many European minds. For example, the Eurobarometer data suggest that the perceptions of risk and of a lack of benefit are closely related. A detailed analysis of the survey data shows that when asked about the "risk," "benefit," and "moral acceptability" of an application such as GM food, as well as whether such an application should be 
encouraged, the lack of benefit is more closely linked to the rejection of "should be encouraged" than the perceived presence of risk (Gaskell et al. 2001a).

\section{Cowardly Governments}

A third explanation for the "anti-GMO" policy in Europe is that governments cowardly gave in to public (or tabloid press and NGO) pressure. In Austria, there was indeed a heavy campaign by NGOs against agricultural biotechnology in 1997, supported by the country's biggest tabloid. By and large, however, policy did not change a lot in response to the campaign, which is not surprising, because expressed public opinion came after rather than before official policy.

Dating back to the early 1990s, this policy line had long been established irrespective of open public pressure while taking into account the latent unease. The research landscape was small and diverse, scientists were not accustomed to going public, and there were no big seed or agricultural biotechnology companies. Thus, restrictions on agricultural biotechnology helped the Austrian government gain credibility with critics without jeopardizing the prospects for the more promising medical applications (Torgersen et al. forthcoming). The biotechnology law of 1994 (adopted before Austria joined the EU) stated a division of labor between different government agencies (Torgersen and Seifert 2000). Responsibility for GMO release and marketing applications were assigned to the Environment Agency, which not surprisingly saw its task as preventing possible environmental harm. Together with the precautionary principle, which was already explicitly stated in the law, such a setup provided the basis for restrictions. For example, a ban of transgenic Bt maize that conflicted with the pertaining EU permit built on an agency assessment from mid-1996. To some experts outside Austria, including EU officials, the arguments presented in this assessment did not appear to be sufficiently informed by independent (i.e., mainstream) science. A short glance at the performance of the Scientific Advisory Committee on Biotechnology supports the argument that in Austria, the scientific community was indeed less influential on biotechnology decision making than regulators. The committee's advice was rarely considered decisive while governmental in-house scientists had the prerogative, which in this case coincided with a nonorthodox opinion.

U.S. regulators in particular often claim that regulatory science (Jasanoff 1995) also has an impact on public opinion. The argument goes that if only "sound science" would prevail in policy advice on biotechnology, the public 
would trust in regulatory bodies and their decisions. In the wake of food scandals, the European Commission and member countries such as the United Kingdom seemed to follow this line of thought and made the systems responsible, respectively, for food safety and the assessment of GM products more independent. While this is surely a step forward, it is still questionable whether it would have enhanced acceptance if regulatory decisions on GM varieties in Austria had closely followed scientific mainstream arguments. In Austria, market breakdowns due to food scandals were mostly manifestations of consumers distrusting the system of industrial agriculture rather than particular food safety agencies and their scientific basis of operation - otherwise, the ensuing boom in organic food and farmers' markets would be hard to explain. Considering the symbolic value of agricultural biotechnology as a proxy for industrialized agriculture in more than one European country, it remains to be seen whether additional surveillance will secure its successful introduction.

\section{Agricultural Protectionism}

North American politicians and industry representatives have sometimes suspected that the EU puts up nontariff trade barriers to block more competitive American agricultural products, exploiting differences in their considerations of possible risks. Although assessment criteria are basically the same, most current regulatory debates between the EU and North America center on divergent risk. There is, however, a more fundamental difference in the perception of usefulness. The North American view implicitly assumes that apart from sound science that could mandate preventive measures, the only legitimate criterion is productivity in terms of yield versus cost and that economies of scale play a decisive role. GM varieties increase productivity and are therefore highly useful and welcome. For many Europeans, however, and Austrians in particular, such crop plants not only are unnecessary in an inelastic market but also bring about societal hazards irrespective of environmental or health risks. Economic considerations center on the fear that GMOs could add to existing surplus problems, so the European Commission as well as many national governments struggle to reduce overproduction. North American policies, in contrast, seek to solve the problem via export promotion, which inevitably gets into conflict with the EU's regulation on GM crops.

The economic aspect goes along with an emotional one. While agriculture in North America is considered an industry, and nobody would normally think of leisurely strolling through wheat fields, the Austrian relation to the 
countryside, for example, is more "romantic." Considerable parts of the Austrian landscape do not render themselves to large-scale industrial farming, and there are still many family farms. Austrian and foreign tourists spend their holidays in rural areas and consider them to be "natural" even if cultivated and to be kept in the interest of country life and an intact landscape. Applying only commercial considerations to agriculture is a mistake to many, although some may also think of revenues from tourism. Consequently, there was always support both from national governments and the European Commission, despite high costs, for agricultural areas that would not match sheer productivity goals but were considered societal and environmental assets. Additionally, and as a way to cope with the increased competition when Austria joined the EU in 1995, the government offered small farmers the opportunity to gain an income from a niche market by subsidizing the conversion to organic production. This coincided with the rising debate on agricultural biotechnology. Wrongly or not, GM crops became a contrasting symbol for large-scale industrial agriculture producing "adulterated" food that threatened organic production, which in turn served as a symbol for family farms producing "natural" food.

When United States-grown GM crops arrived in late 1995, the pending adoption of GM-based agriculture in Europe also appeared to contradict policy aims officially supported both by the European Commission and the Austrian government. The conflict thus not only was about risk and its assessment and management, as the official statements would suggest; rather, it was about the understanding of the tasks and properties of agriculture and, by implication, of the rural area. If agriculture is but an industry sector, only the

producers should decide about the methods applied. If, however, the public should have a say on how its food should be produced and how the domestic landscape should look, this would interfere with property rights. In the United States, such interference would be deemed illegitimate. However, in Austria, as in many other European countries, food production, landscape, and the shape of the rural area are indeed considered publicly relevant issues. In the sense that there should be some limits to competition on productivity only, one can say that Europe leans toward a kind of protectionism, but for less blunt reasons than Europeans are sometimes alleged to (Figure 3).

\section{Closing the Gap?}

Framing the conflict as being about consumer choice and risk, the European Commission has subscribed to mandatory labeling and the 


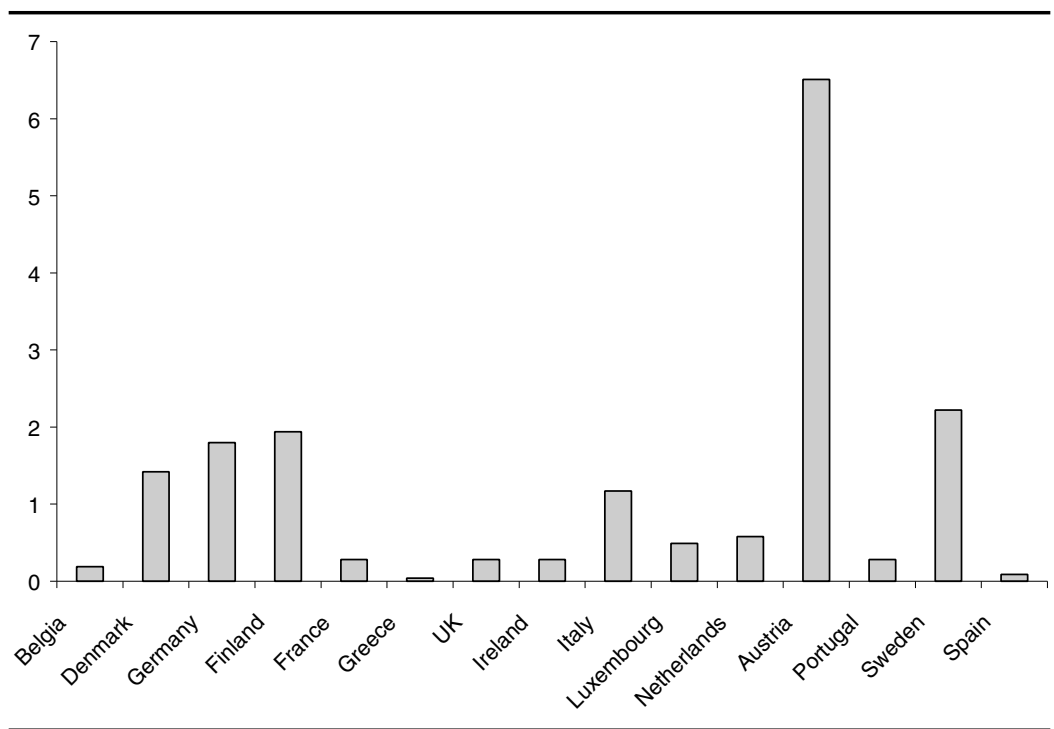

Figure 3: Percentage Organic Acreage

SOURCE: Austrian Ministry of Agriculture (2001).

precautionary principle - policy tools Austria had long been promoting. The precautionary principle in particular is a red flag to many U.S. regulators because they perceive it to be entirely unscientific and undetermined. Closing the gap, in a U.S. understanding, would entail the EU adopting the sound science approach of U.S. regulation and no longer demanding that GM products be subject to mandatory labeling. While the EU emphasizes the scientific basis of its approach and tries to operationalize the precautionary principle, it may face a complaint before the World Trade Organization. Conversely, there is a certain export from Europe into the United States of consumer reluctance against GM food products, prompting some American retailers and food chains to adopt non-GM product lines. Surveys show that attitudes indeed are less different than frequently assumed, although the acceptance of GM products still is higher west of the Atlantic (Priest 2000). However, even if there are some hesitant consumers in the United States and increasing competition in Europe, there still remains one pervasive difference. The consideration of economic competitiveness as an asset, almost irrespective of who benefits, will always conflict with the perception of agriculture as a multifunctional sector that must not be exclusively governed by economic imperatives. Closing this cultural gap will be hard to achieve. 


\section{Note}

1. Although different definitions of the precautionary principle exist, the following is considered a more canonical one (Montague 1998): "When an activity raises threats of harm to human health or the environment, precautionary measures should be taken even if some cause and effect

relationships are not fully established scientifically."

\section{References}

Austrian Ministry of Agriculture. 2001. Homepage in organically cultivated areas in the European Union [table]. Retrieved from http://artifex.lfrz.at:8007/duz/enduser/results.jsp? outlang $=0$ \&bnr $=23$

Gaskell, G., N. Allum, W. Wagner, T. H. Nielsen, E. Jelsoe, M. Kohring, and M. Bauer. 2001a. In the public eye: Representations of biotechnology in Europe. In Biotechnology in the public eye, edited by G. Gaskell and M. Bauer, 53-79. London: Science Museum.

Gaskell, G., E. Einsiedel, S. Priest, T. Ten Eyck, N. Allum, and H. Torgersen. 2001b. Troubled waters-The Atlantic divide on biotechnology policy. In Biotechnology in the public eye, edited by G. Gaskell and M. Bauer, 96-115. London: Science Museum.

Grabner, P., and H. Torgersen. 1998. Österreichs gentechnikpolitik-Technikkritische vorreiterrolle oder modernisierungsverweigerung? Österreichische Zeitschrift für Politikwissenschaft 1:5-27.

Jasanoff, S. 1995. Product, process or programme: Three cultures and the regulation of biotechnology. In Resistance to new technology: Nuclear power, information technology and biotechnology, edited by M. Bauer, 311-31. Cambridge, UK: Cambridge University Press.

Montague, P. 1998. The precautionary principle. Rachel's Environment and Health Weekly. Available: http://www.biotech-info.net/rachels_586.html

Priest, S. 2000. US public opinion divided over biotechnology? Nature Biotechnology 18:93942.

Torgersen, H., C. Egger, P. Grabner, N. Kronberger, F. Seifert, P. Weger, and W. Wagner. 2001. Austria: Narrowing the gap to Europe. In Biotechnology 1996-2000: The years of controversy, edited by G. Gaskell and M. Bauer, 131-44. London: Science Museum.

Torgersen, H., J. Hampel, M.-L. von Bergmann-Winberg, E. Bridgman, J. Durant, E. Einsiedel, B. Fjaestad, G. Gaskell, P. Grabner, P. Hieber, E. Jelsoe, J. Lassen, A. Marouda-Chatjoulis, T. Nielsen, T. Rusanen, G. Sakellaris, F. Seifert, C. Smink, T. Twardowski, and M. W. Kamara. 2002. Promise, problems and proxies: 25 years of European debate and regulation. In Biotechnology: The making of a global controversy, edited by M. W. Bauer and G. Gaskell, 21-94. Cambridge, UK: Cambridge University Press.

Torgersen, H., and F. Seifert. 1997. Aversion preceding rejection: Results of the Eurobarometer survey 39.1 on biotechnology and genetic engineering in Austria. Public Understanding of Science 6:1-12.

. 2000. Precautionary blockage of agricultural biotechnology. Journal of Risk Research 3 (3): 209-217.

Wagner, W., N. Kronberger, G. Gaskell, A. Allansdottir, N. Allum, S. de Cheveigné, U. Dahinden, C. Diego, L. Montali, A. T. Mortensen, U. Pfenning, T. Rusanen, and N. Seger. 2001. Nature in disorder: The troubled public of biotechnology. In Biotechnology in the public eye, edited by G. Gaskell and M. Bauer, 80-95. London: Science Museum. 
HELGE TORGERSEN is a senior researcher at the Institute of Technology Assessment of the Austrian Academy of Sciences. His research interests include biotechnology policy and the safety regulation of transgenic organisms, the relation between risk assessment and public perception, and methods of participatory technology assessment. 